\title{
Digital Humanities: Community Participation in the Balinese Language Digital Dictionary
}

\author{
Cokorda Pramartha* \\ Department of Informatics, \\ Udayana University \\ Bali, 80361, Indonesia \\ cokorda@unud.ac.id
}

\author{
Ida Bagus Ary Indra Iswara \\ Department of Informatics, \\ STIKI Indonesia \\ Bali, 80225, Indonesia \\ indraiswara@stiki-indonesia.ac.id
}

\author{
I Komang Ari Mogi \\ Department of Informatics, \\ Udayana University \\ Bali, 80361, Indonesia \\ arimogi@unud.ac.id
}

\begin{abstract}
In recent years, the capability of Balinese people to write and speak their mother tongue has declined significantly among the younger generations because of the growing influence and adoption of the national language, Bahasa Indonesia. It has spread rapidly among Balinese youth because it is considerably more straightforward than the Balinese language and is free of caste regulations. In this paper, we present the details of our digital humanities preservation research dealing with the Balinese language. We utilize community-based crowdsourcing to participate in expanding and enriching the BASABali Wiki digital dictionary in the form of an online competition. Ninety-six participants in 24 groups participated in our study, and their contribution populated 2686 new unique sentences to the BASABali Wiki digital dictionary. We also discuss the procedures employed to evaluate the digital dictionary: to receive feedback on the digital dictionary system and our approach to acquiring the knowledge of the community.
\end{abstract}

Keywords: Digital dictionary, balinese language, digital humanities, community-based crowdsourcing

\section{Introduction}

The island of Bali is one of the small islands of the Indonesian archipelago and has a diverse and rich culture. This island is also known as the most significant international and national tourist destination in Indonesia. The rich culture and heritage of Bali has become one of the most exciting attractions to people visiting this island. The Balinese people have maintained their heritage and tradition through religious ritual and daily practices. The Balinese cultural knowledge and practices have been passed down over generations through socialization: each generation learns by experience through ritual and tradition. However, as modern commercialism and standardization have started to replace the traditional

* Corresponding Author 
mode of socialization to transfer cultural knowledge, with its poor documentation, there is great concern that the Balinese culture will vanish in the future (Covarrubias 2008; Pramartha and Davis 2016).

The phenomenon of the extinction of indigenous languages in Indonesia has become a significant concern for many scientists, especially linguists. Various efforts have been made to safeguard these indigenous languages from the process of extinction. This is a justifiable concern for Indonesia, which is recognized as the second-largest country in the world that practices indigenous languages, after Papua New Guinea. Some of these languages are classified as Austronesian languages, and some are nonAustronesian (Papuan) languages. The extinction of the language has implications not only for the linguistic domain, which focuses on the structural aspects of the language, but also the cultural knowledge that is attached to the language. This is because through language, a community's perspective can be understood, and the rules, traditions, and beliefs of an ethnic group can be shown (Dixon 1997).

The Balinese language is one of 719 living languages spoken in Indonesia and is mainly used on the islands of Bali and Lombok. According to the latest survey from the Summer Institute of Linguistics (SIL), only 707 mother-tongue languages are spoken in Indonesia. This number is based on the communities that continue to communicate using these languages. However, The United Nations Educational, Scientific, and Cultural Organization (UNESCO) has registered only 143 languages from Indonesia on their database (Kemdikbud 2018).

There are three layers of the Balinese language: the low (base bali sor), common or middle (base bali madya), and high tongues (base bali alus). As one of the legendary anthropologists of Balinese culture writes, "The high and low tongues are distinct, unrelated languages with separate roots, different words, and extremely dissimilar character" (Covarrubias 2008). These three layers of Balinese language are linked to a hierarchy of castes that are regulated in the Balinese social system. The hierarchy of castes in the Balinese social system are: 1) Brahmana, a family of the high priests; 2) Kshatriya, mainly the royal family and kings, who acted as warriors in the past; 3) Waisya, a group who work as traders or government officials; and 4) Sudra, a group of people who generally work as farmers. Communicating in different layers of the Balinese language is vital in the Balinese social system and community.

Today, the Balinese people are experiencing a cultural heritage knowledge erosion: specifically, the use and understanding of Balinese language. This is due to the global cultural influence, and the extensive use of Bahasa Indonesia in all school grades makes this indigenous language preservation more challenging. Sooner or later, with a few people practicing and understanding the Balinese language, it and the related heritage are likely to vanish. Moreover, as the younger generation of Balinese have a limited understanding of the Balinese cultural heritage, they try to avoid using the different layers of the Balinese language in communication. A recent study has estimated that the current Balinese generation may be the last generation that can speak the Balinese language if no additional action is taken to preserve the language (Beratha et al. 2017).

Recently, Balinese language and culture strengthening initiatives undertaken by the public sectors have increased. The latest Balinese Governor, I Wayan Koster, releases a regulation number 10-year 2018 related to the use of the Balinese language, script, and customary clothes (pakaian adat) every Thursday. Also, these regulations force the public and private sector to write the title of the office or the event in the Balinese script. Through this regulation, since 2018, every February is used as a month to celebrate a Balinese culture, with many activities such as ancient text transcribing, Balinese storytelling, scriptwriting, and so forth.

To counter the Balinese language degradation within the younger generation, there are some initiatives supported by public organizations that aim to encourage young Balinese to continue their heritage. In 2013, a digital project (Tamiang) that aims to help Balinese people preserve their ability to use the Balinese scripts in a digital form was initiated by Pramartha and Dwidasmara (2014). This study is a collaborative project between Udayana University and Denpasar Vocational High School (SMKN1 Denpasar) with a research grant from the Denpasar City Council (the capital city of Bali). The Tamiang project focuses on developing a non-QWERTY computer keyboard that can be utilized to write Balinese 
script in a digital form. Today, this project has received full support from Udayana University to produce a prototype and is expected to release and distribute the final product throughout all schools in Bali.

Today, the opportunities for cultural heritage and humanities preservation can be assisted by the adoption of digital technology such as mobile technology and the Internet. The rapid development and adoption of these technologies can connect those people who have and understand the cultural knowledge with people who want to learn heritage knowledge.

In this paper, we discuss our approach to preserving the rich and diverse Balinese cultural heritage by expanding the Balinese language digital dictionary in the form of a knowledge-based system (www.basabali.org) that can be accessed and learned by the student, community, and the Balinese younger generation, in particular, using a computing device, such as mobile device or computer, and the Internet. Using this knowledge-based system in the form of a digital dictionary, the community can contribute by adding, refining, and sharing heritage content related to the Balinese language. Moreover, much of the digital dictionary content relies on community participation in the form of crowdsourcing. Furthermore, this paper also adopted the Technology Acceptance Model (TAM) (Davis et al. 1989) to assess the ease of use and usefulness of the knowledge-based system in relation to the community contribution.

\section{Literature Review}

\section{Digital Language Revitalization}

Over the past few decades, the concern about language endangerment and cultural heritage loss has increased significantly. Many multi-disciplinary and collaborative projects have been developed that focus on language mitigation and large-scale diversity destruction due to globalization. The involvement of the community of native speakers in the project becomes essential to capture and understand the language and the cultural knowledge surrounding the language (Genee and Junker 2018).

Today, digital technology has become a commodity that is affordable and accessible to anyone. It is clear that many areas of the humanities have been supported by this digital technology; for instance, in indigenous language revitalization and reclamation (Galla 2016). Moreover, successful efforts in language revitalization around the world are mainly based on community initiative, commitment, and investment (Fishman 2001).

On the other hand, while some academic articles have mentioned that digital technology has improved language learning, there are few published studies on the integration between technology and indigenous language revitalization. Hermes and King (2013) suggest that to preserve the indigenous language using technology, the community should adopt this technology in three different areas:

1. Communication. The broad adoption of digital technology, such as the Internet, as a community communication medium, specifically for indigenous languages, provides a new context of usefulness. Also, the Internet enables the communication to reach not only locals but people on the other side of the globe.

2. Materials production. Digital technology enables users to produce, reuse, and share digital resources in the context of indigenous language easily.

3. Documentation. This last area has become important: documenting and archiving any knowledge in digital form performs a major role in supporting revitalization efforts.

A digital project on the revitalization of the endangered Torwali language used digital technology to develop a database to support knowledge-based systems. The initial project collected data from students, colleagues, friends and relatives of the author, without providing information on their background related to the language being studied (Ullah 2019). A significant work by Genee and Junker (2018) that focused on developing Blackfoot language resources and a digital dictionary, using web technology to capture and store the digital resources, has provided positive evidence of language revitalization. Their work involved and empowered community participation to add to and refine the resources. Both of these language preservation projects had a different approach and methodology to 
our project, in which community contributions to preserve the language are in the form of a competition, and Balinese language experts are used to verify the participant contributions. Moreover, as previously stated, the complexity of the three different levels of Balinese language ("basa bali alus", "basa bali madya", and "basa bali sor") adds another challenge to the task of preservation in our study.

\section{Crowdsourcing Approach in Digital Humanities and Heritage}

In 2006, Howe introduced the term 'crowdsourcing' for the first time in Wired magazine to describe "the act of taking a job traditionally performed by a designated agent (usually an employee) and then outsourcing it to an undefined, generally large group of people in the form of an open call". This definition was then expanded by Brabham (2013), who suggested that crowdsourcing is something initiated by an organization, not by a group of individuals. Moreover, crowdsourcing is something that employs many people on the Internet (Mao et al. 2017).

Today, many cultural heritage organizations, such as galleries, libraries, archives and museums (GLAMs) have utilized this approach, which allows the public to participate in undertaking cultural heritage tasks. For instance, a study at the National Library of Australia utilized crowdsourcing to correct and transcribe almost 320,000 articles from The Australian newspaper, with seven million lines transcribed in just one year. Similarly, a project to transcribe approximately 124,000 Bentham manuscripts was hosted by University College London (Alam and Campbell 2017).

Initially, many people and organizations, especially in the cultural heritage domain, expressed doubts about utilizing crowdsourcing to achieve their goals. However, a study by Corney et al. (2010) provided substantial evidence on employing crowdsourcing in a cultural heritage project, specifically in translation tasks, and showed that crowdsourcing had a 77\% success rate. Other studies, of the Bentham project (Causer and Terras 2014) and the Papers of the War Department project (Leon 2014), also agree that involving crowdsourcing in a transcription project leads to a higher success rate than when text on paper is scanned and automatically transcribed using computer software. Another study on capturing and annotating cultural objects by crowdsourcing claims that the various backgrounds and understanding among crowdsourcing employees will provide diverse points of view to capture the breadth and richness of the cultural resources (Constantinidis 2016).

Crowdsourcing typically comprises a large number of users or workforces on the Internet to solve a complex problem. However, including a specific kind of crowdsourcing, such as community-based crowdsourcing (CBC) (de Vreede et al. 2017) to work on a particular kind of problem or project will give a more successful outcome. A recent study by Pramartha et al. (2017) shows that CBC participation in populating Balinese cultural heritage knowledge, specifically on the Balinese traditional communication tool ("kulkul"), into a digital portal has contributed a significant amount of data to the digital portal with substantial quality. Moreover, the expert domain participation and their levels of experience and expertise are linked to the knowledge being acquired using the $\mathrm{CBC}$ approach.

\section{Methodology}

In this study, the researchers focused on acquiring knowledge of Balinese language from the community. A 24-hour online competition was conducted by the researchers, in which the participants were asked to populate as many sample sentences as possible either in the Balinese language high tongue ("basa bali alus") or the Balinese language common tongue ("basa bali madya") to the BASABali Wiki digital dictionary and virtual library (details of the procedure explained in the next section). After the sample sentences were submitted to the BASABali Wiki digital dictionary system, submitted contents were checked for correctness by the Balinese language experts. The researchers focused this study in two different geographical locations: Bali (Universitas Udayana campus, Bali and STIKI STIKOM Indonesia), and in the city of Jakarta.

\section{BASABali Wiki Digital Dictionary System}

The BASABali Wiki digital dictionary system is a wiki-based system and a self-registered system that has been available online at www.basabali.org since 2014. This wiki serves as a digital dictionary for 
the Balinese language and is expected to be the main reference for those who would like to learn and document the Balinese language in digital form. Within nearly five years there were 5,452 registered users with 12,654 Balinese words and sample sentences entered in the system. Currently, the BASABali Wiki contents rely heavily on the Balinese language expert team that works side-by-side to populate most of the content. Furthermore, the BASABali Wiki digital dictionary system is designed to support the public to contribute content using the Internet-based technology. This BASABali wiki digital dictionary system lacks a mechanism to control the populated data, meaning any registered user can post, edit, and delete any content at the wiki and publish it without anyone from the Balinese language expert moderating the content in advance. However, the expert team can delete edits from the public and revert to a previous version.

\section{Participant and Cultural Expert Recruitment}

In this study, we recruited participants from the student and staff network of the Udayana University and STIKI Indonesia, the Balinese community in Bali, and the Balinese community in Jakarta. The Udayana University was chosen for this project because of its standing as a repository of Balinese cultural knowledge and expertise. The STIMIK STIKOM Indonesia was selected because this School of Information Technology has a focus on supporting the preservation of Balinese cultural heritage using digital technology. The majority of students from both universities are Balinese. The Balinese community in Jakarta was invited because @america, the center for American culture in Indonesia, which is in Jakarta, was involved to support this study. Posters were placed around the university campuses and in high schools in Jakarta with a brief overview of the study and details of a contact person in charge of the competition.

Participant recruitment is shown in Figure 1. In order to participate, it was not mandatory to be part of this project that a participant be a student or staff member of the university or Balinese community. The only requirement was that the participants should be in groups of four or five people, and that any of the team members should have knowledge about the Balinese language. Participants who decided to be involved in the study were asked to fill in an online form to register their team details, including their members' information. Once the participants agreed to take part in this study, they were provided with a short training session, conducted either in-person or using a tutorial video that was provided on the website. The short training was conducted for a small number of groups by the research team in Denpasar. Participants that live outside the Denpasar city were provided with the tutorial video. There were 44 teams that responded to our invitation; however, during the competition only 24 teams comprising a total of 94 participants decided to compete. At the end of the study, all participants that interacted with and experienced the system were invited to take part in the evaluation by taking the online questionnaire.

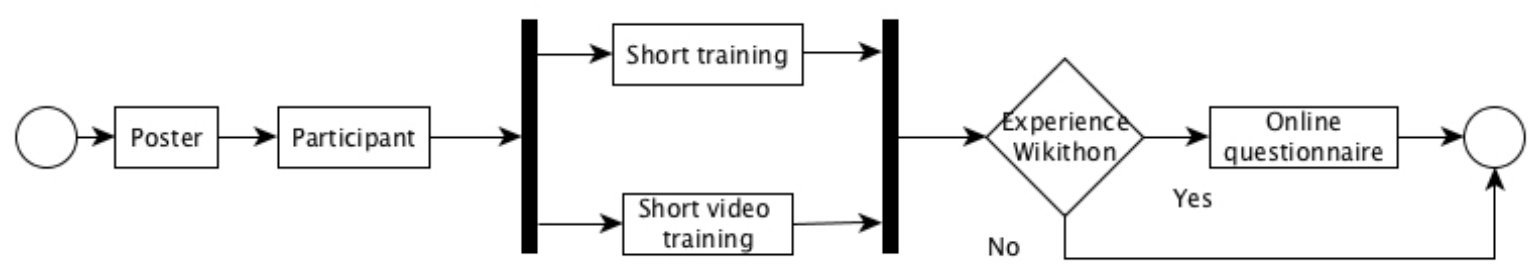

Figure 1. Participant recruitment

All data submitted by the participants was assessed by the Balinese cultural experts. We recruited eight Balinese language experts to assess all data submitted by the community and ensure that it was of sufficient quality:

1. Three professors from the Faculty of Culture and Art at Udayana University - Bali.

2. Two practitioners with more than 10 years' experience in the Balinese language.

3. A professor from Sekolah Tinggi Agama Hindu Negeri, Singaraja - Bali.

4. A senior librarian from Lontar Library at Universitas Udayana - Bali.

5. A senior editor of a Balinese dictionary at Balai Bahasa, Bali Province. 
Each of the experts had more than 10 years' experience in their field.

\section{Participants' Task}

In this digital humanity knowledge acquisition study, as mentioned previously, the researchers ran the community participation in the form of an online competition over 24 hours. These 24 hours of community participation were divided into several sessions. In each session, the participating team had two hours to contribute their Balinese language knowledge to the wiki system. At the end of each twohour session, the Balinese cultural experts acted as judges to review and assess the participants' contributions. The team that won each session was announced via the social media platforms Facebook and Twitter. Also, they were awarded a USD50 voucher that had been donated by a national and international organization that cares about Balinese culture.

All participants requested to submit their content to https://dictionary.basabali.org. Figure 2 is a flowchart of how the participants participated in the online competition. Usernames and passwords were provided by a member of the research team to the participants manually. This made it easier for the reviewer to evaluate participants' contributions and decide the winner for each session. Once the participants successfully logged in to the system, they were provided with random Balinese words without sample Balinese sentences to go with them. The participant was prompted to populate a Balinese sample sentence based on the random word that appeared on their screen. However, the participant could skip a word and continue to another random Balinese word if they did not understand the word or it was difficult for them to provide a sample sentence. Figure 3 is an example of a sample sentence being entered into the system by the participant. In an example shown in Figure 3, the participant populated the word "lelucon" (funny) into a sentence: "Dalange ento ngawyang lelucon kanti tiang kedek ngakak" (The puppeteer is telling a funny story and makes me laugh).

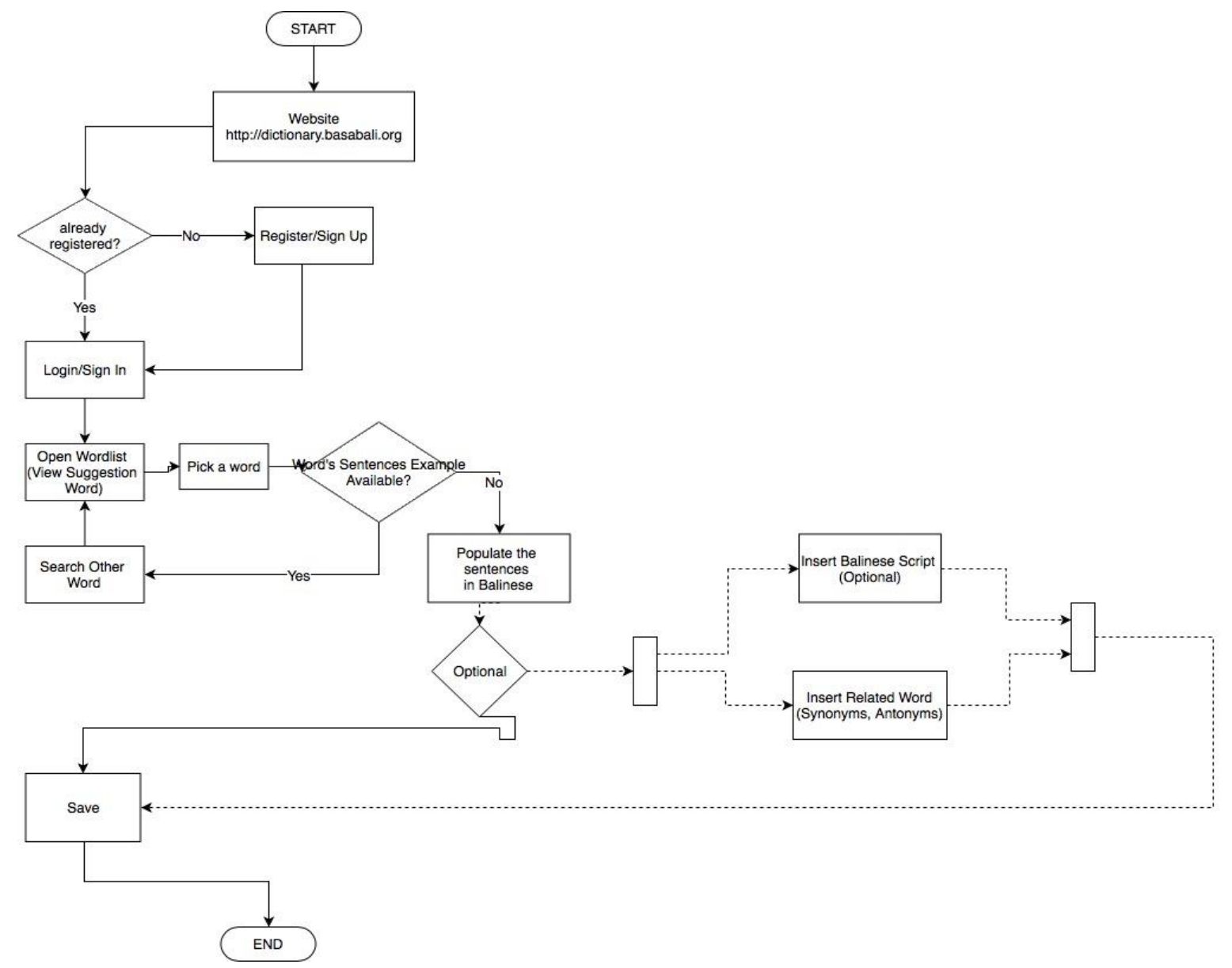

Figure 2. Participants' task 


\section{Lelucon}
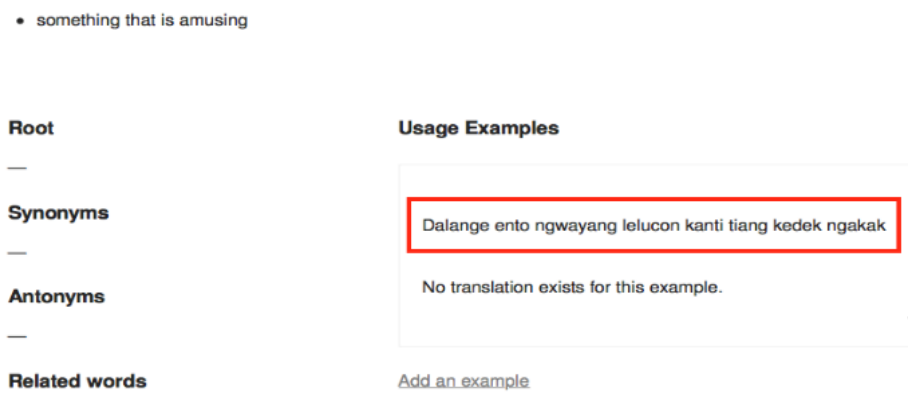

Figure 3. Example of populated sentence

\section{Evaluation of Community-Based Crowdsourcing Contributions}

\section{Perceived Ease of Use and Perceived Usefulness}

Technology Acceptance Model (TAM) is a model that is used to evaluate user acceptance of information systems (Davis et al. 1989; Hasanah et al. 2019). This model uses two variables - perceived usefulness and perceived ease of use (Suarta and Suwintana 2015) - to explain users attitudes toward using an information system (see Figure 4).

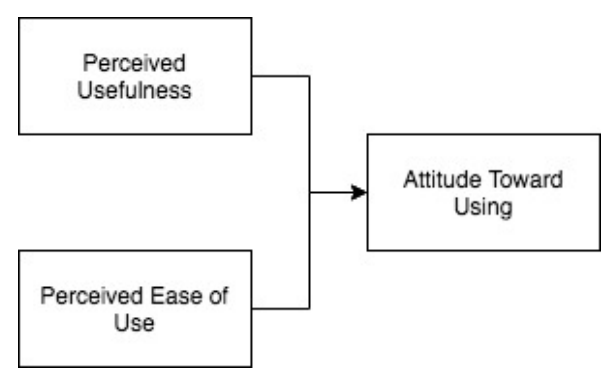

Figure 4. Technology Acceptance Model (TAM): Attitude toward using an information system

Perceived usefulness is defined as "the degree to which a person believes that using a particular system would enhance his or her job performance", and perceived ease of use refers to "the degree to which a person believes that using a particular system would be free of effort" (Davis 1989). The perceived usefulness (PU) of the BASABali Wiki comprised six variables:

1. Using the BASABali Wiki would enable me to accomplish tasks more quickly.

2. Using the BASABali Wiki would improve my task performance.

3. Using the BASABali Wiki in my task would increase my productivity.

4. Using the BASABali Wiki would enhance my effectiveness in performing my tasks.

5. Using the BASABali Wiki would make it easier to do my tasks.

6. I would find the BASABali Wiki useful to finish my tasks.

The perceived ease of use (PE) of the BASABali Wiki included six variables:

1. Learning to operate the BASABali Wiki would be easy for me.

2. I would find it easy to get the BASABali Wiki to do what I want it to do.

3. My interaction with the BASABali Wiki would be clear and understandable.

4. I would find the BASABali Wiki to be flexible to interact with.

5. It would be easy for me to become skilful at using the BASABali Wiki.

6. I would find the BASABali Wiki easy to use.

The variables of the participants' perceived usefulness (PU) and perceived ease of use (PE) were measured using a 7 -point Likert scale $(1=$ strongly disagree, to $7=$ strongly agree $)$. Aside from 
responding to the PU and PE question, participants can add further suggestions and comments. The initial questionnaire of PU and PE were in English, and we provided the instrument to targeted participants in Bahasa Indonesia. To cope with different languages, we adopted the back-translation method (Brislin 1970) to make sure the reliability of the instrument when applying it in different languages.

\section{Participant Motivation}

This study relied heavily on community contribution to add, refine, and share digital humanities knowledge and content in the form of Balinese language. As previously mentioned, we offered a USD50 prize for the winning team in each session. A study by Litman et al. (2015) showed that participant contributions and the quality of work in a crowdsourcing project are related to monetary compensation (Litman et al. 2015). On the other hand, some projects in relation to humanities and cultural heritage preservation engage participants or volunteers without monetary compensation; instead, their participation relies more on the engagement of participants and their feeling of belonging to the culture being preserved (Alam and Campbell 2017).

\section{Result}

Evaluation is a critical step in this study to understand the participants' contributions. Specifically, in this study, the researcher evaluated the number of participants' contributions, which were the sample sentences entered into the BASABali Wiki digital dictionary system. Moreover, the participants' experience with the system was also evaluated to improve the performance of the BASABali Wiki digital dictionary system.

\section{Community Contribution}

As mentioned previously, all participants were provided with a list of computer-generated words that lack sample sentences. The program was designed such that only one group of participants would work on a given random word at any one time. Within 24 hours, 2686 new unique sentences were added (see Table 1). The percentage of contributions from each team is shown in Figure 5. All new and unique sentences created by the 96 participants in 24 teams that competed in this study were counted. In our observation on the system logs, four to eight groups participated in each two-hour session. By the end of each session, new sentences were checked by Balinese language experts for quality. The quality was checked using a simple three-point scale: $0=$ incorrect, $1=$ somewhat correct and $2=$ correct. According to the experts, all sentences met the minimum standard to be published online for public consumption. The minimum standard was 'somewhat correct', which meant that the sentence submitted by participants could be understood, but the structure ("anggah ungguh"), such as whether they used the high tone for the sentence, or they mixed the tone, was not correct.

After all the participants had completed the online competition, they were invited to answer a small set of questions regarding the ease of use and usefulness of the BASABali Wiki digital dictionary system. The researchers adopted the instrument of two dimensions: perceived usefulness (PU) and perceived ease of use (PE) (Davis 1989).

The SPSS statistical analyses tool were used to analyse the outcome of the questionaire. In order to check the items consistency of the questionnaires, a relibility test (Cronbach's alpha) was conducted. Moreover, to conclude that BASABali Wiki digital dictionary system is useful and easy to use, a onesample t-test was performed. 
Table 1. Frequency of contributions

\begin{tabular}{|l|r|}
\hline \multicolumn{1}{|c|}{ Groups } & Number of unique sentences \\
\hline Denpasar13 & 498 \\
\hline Karangasem3 & 395 \\
\hline Tabanan1 & 367 \\
\hline Denpasar17 & 332 \\
\hline Denpasar19 & 330 \\
\hline Denpasar11 & 244 \\
\hline Denpasar16 & 243 \\
\hline Singaraja2 & 92 \\
\hline Greenschool2 & 40 \\
\hline Denpasar18 & 32 \\
\hline Others & 113 \\
\hline Total & $\mathbf{2 , 6 8 6}$ \\
\hline
\end{tabular}

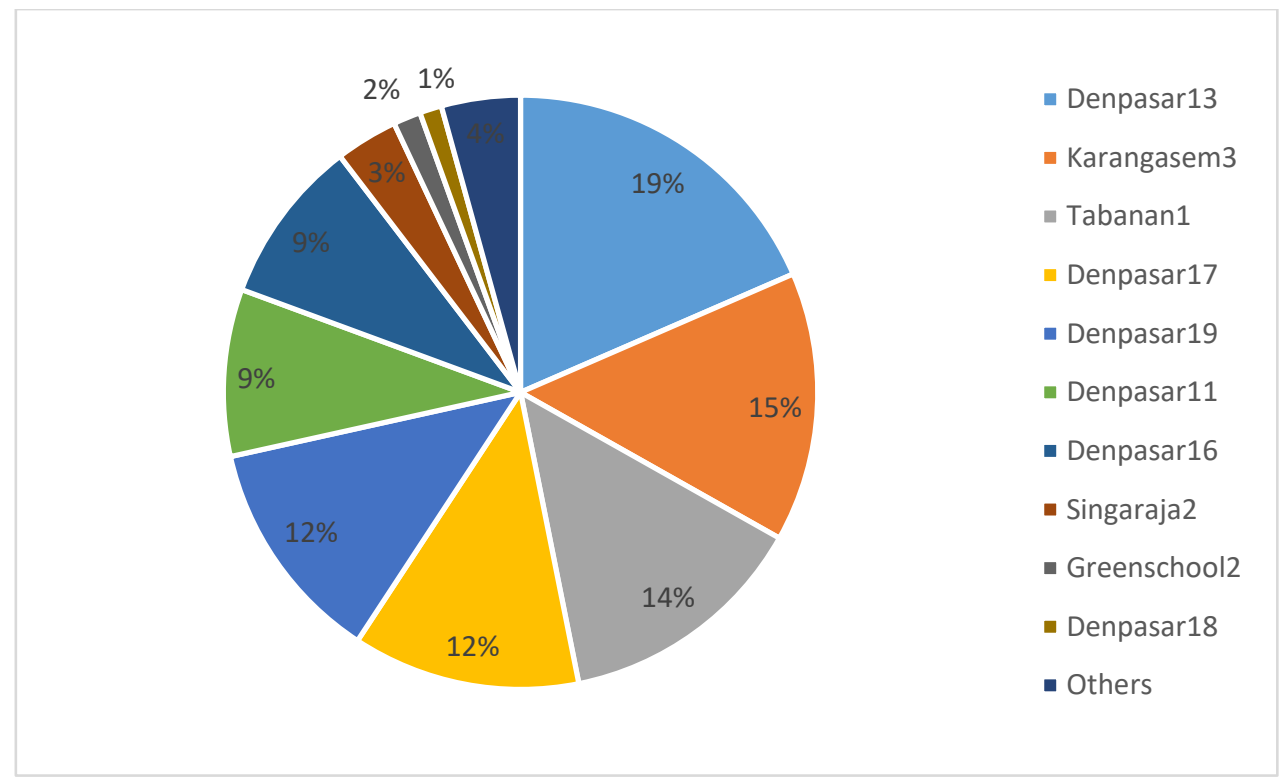

Figure 5. Percentage of contributions

Other analyses, such as Kaiser-Meyer-Olkin (KMO) Measure of Sampling Adequacy analysis, were performed to ensure that there was adequately high variability in the collected data for factor analysis. However, due to the limitations of the data collected the KMO outcome was low, below 0.5, indicating that the data was not suitable for Factor Analysis. A total of 16 participants from 11 different teams responded to our invitation to answer the questionnaire. A detailed characterization of these 16 participants is shown in Table 2. Cronbach's alpha was performed to assess the reliability of the items. As shown in Table 3, the reliabilities of the items are above the minimum threshold of 0.7 (Nunnally and Bernstein 1994), which the calculated alpha of perceived usefulness (PU) was 0.869 and perceived ease of use (PE) was 0.724. For ease of interpretation and to assess users' perceptions of the BASABali Wiki digital dictionary system, we grouped the participants' raw scores on each of the above twocomponent items (PU and PE) into samples PUAVG and PEAVG, respectively, and calculated the mean for each sample (Table 4). Moreover, we treated the above scores with equal weights due to the nature of our exploratory research(Hair et al. 1998; Tabachnick and Fidell 2001). 
Table 2. Participant characteristics

\begin{tabular}{|l|c|}
\hline Description & N \\
\hline Participants & 16 \\
\hline Gender & 11 \\
\hline Male & 5 \\
\hline Female & 15 \\
\hline Religion & 1 \\
\hline Hindu \\
\hline Christian \\
\hline Member of community \\
\hline Banjar \\
\hline Youth community & 1 \\
\hline Balinese orchestra & 9 \\
\hline Other & 1 \\
\hline None & 1 \\
\hline Area of living & 4 \\
\hline City & 10 \\
\hline Rural/suburb & 6 \\
\hline Balinese Language literacy & \\
\hline Poor & 1 \\
\hline Moderate & 4 \\
\hline Advanced & \\
\hline
\end{tabular}

The results of analyses suggest that the users' perceived usefulness score for the BASABali Wiki was statistically considerably higher than the middle point of $4.0, t(15)=25.100, p=0.005, \mathrm{SD}=0.86$, mean $=5.43$. Similarly, the users' perceived ease of use score for the BASABali Wiki was statistically significantly higher than the middle point of $4.0, t(15)=43.859, p=0.005, \mathrm{SD}=0.53$, mean $=5.81$ (see Table 4 and Table 5). In conclusion, the results suggest that in general, the users perceived the usefulness and ease of use of the BASABali Wiki digital dictionary system to be positive.

Table 3. Reliability of Perceived Usefulness and Perceived Ease of Use

\begin{tabular}{|l|l|l|}
\hline Reliability & Cronbach's Alpha & N of Items \\
\hline Perceived Usefulness & .869 & 6 \\
\hline Perceived Ease of Use & .724 & 6 \\
\hline
\end{tabular}

Table 4. One-sample statistics

\begin{tabular}{|l|c|c|r|r|}
\hline & N & Mean & Std. Deviation & Std. Error Mean \\
\hline PUAVG & 16 & 5.4271 & .86489 & .21622 \\
\hline PEAVG & 16 & 5.8125 & .53011 & .13253 \\
\hline
\end{tabular}

Table 5. One-sample t-test

\begin{tabular}{|c|c|c|c|c|c|c|}
\hline & \multicolumn{6}{|c|}{ Test Value $=0$} \\
\hline & \multirow[t]{2}{*}{$\mathbf{t}$} & \multirow[t]{2}{*}{ df } & \multirow[t]{2}{*}{ Sig. (2-tailed) } & \multirow[t]{2}{*}{ Mean Difference } & \multicolumn{2}{|c|}{$\begin{array}{l}\text { 95\% Confidence Interval } \\
\text { of the Difference }\end{array}$} \\
\hline & & & & & Lower & Upper \\
\hline PUAVG & 25.100 & 15 & .005 & 5.42708 & 4.9662 & 5.8879 \\
\hline PEAVG & 43.859 & 15 & .005 & 5.81250 & 5.5300 & 6.0950 \\
\hline
\end{tabular}




\section{Discussion}

\section{Participant Motivation}

Aside from assessing the perceived usefulness and ease of use of the BASABali Wiki, the researchers asked participants about their motivation for this study by providing them with a separate question. Interestingly, none of the participants mentioned that the prize or money was their main motivation to participate in this competition. However, many of them clearly mentioned that they participated in the study to help by contributing their knowledge to preserve the Balinese language. This motivation is in line with Alam and Campbell (2017), who found that money is not the main concern for crowdsourcing participation in the cultural heritage domain.

In the present project, a community was involved as the main contributor to digital language preservation in the form of an online competition, and Balinese language experts were used to verify the participants' contributions. Our project is a bit different in approach and methodology from both the Genee and Junker (2018) and Ullah (2019) language preservation projects. Moreover, the complexity of the three different levels of Balinese language (base bali sor, base bali madya, base bali alus) was another challenge in the preservation project.

\section{Conclusion}

We have presented the details of our study on the digital preservation of the Balinese language using community crowdsourcing with a competition framework. Our contributions include digitization of the Balinese language by inviting the community to participate in an online competition to populate a wiki dictionary with Balinese sentences, making it available on the Internet and evaluating the communitybased contribution.

Our study involved 96 participants in 24 teams from two universities in Bali, and Balinese communities in Bali and Jakarta, who populated content to the BASAbali Wiki digital dictionary system. In this study, online participants successfully generated 2686 new unique sentences in the BASAbali Wiki dictionary systems during 24 hours of online competition. At the end of the online competition, we evaluated the system features in term of ease of use and usefulness. The results indicate that, for the most part, the users perceived the usefulness and ease of use of the BASAbali Wiki digital dictionary system to be positive. Moreover, all participants clearly mentioned that money was not their main motivation. Instead, they wanted to contribute knowledge to digital humanities by preserving the Balinese language mother tongue in a digital form, indicating positive feedback on this project.

Currently, we work to promote this BASAbali Wiki digital dictionary system among the schools and communities in Bali. We expect the community is not only using and benefiting from the available content, but that the community should also contribute their knowledge to expand this system to be a living repository.

We acknowledge that our study has some limitations; for example, during the study we did not fully control the system environment to be available only to the participants. Other users were also able to access and write data to the BASAbali Wiki Digital dictionary system during the competition. Also, we should have registered every team member and provided each of them with a unique username, so that we could analyze each member's contribution and effort in greater detail rather than as an aggregate contribution of the team.

\section{Acknowledgments}

This study received funding from Udayana University [grant no. B/20-78/UNI14.4.A/PT.01.05/2020]. Also, we would like to thank BASABali Wiki for providing us access to the system and data in order to conduct this study. We also appreciate all participants' efforts to contribute their knowledge to enrich the BASABali Wiki digital dictionary system and make it available for the public. 


\section{Disclosure Statement}

On behalf of all authors, the corresponding author states that there is no conflict of interest.

\section{References}

Alam, S. L., and Campbell, J. 2017. "Temporal Motivations of Volunteers to Participate in Cultural Crowdsourcing Work," Information Systems Research (28:4), pp. 744-759.

Beratha, N. L. S., Sukarini, N. W., and Rajeg, I. M. 2017. "Balinese Language Ecology: Study About Language Diversity in Tourism Area at Ubud Village," Jurnal Kajian Bali (7:2), pp. 121-134.

Brabham, D. C. 2013. Crowdsourcing. Cambridge, Massachusetts: Mit Press.

Brislin, R. W. 1970. "Back-Translation for Cross-Cultural Research," Journal of cross-cultural psychology (1:3), pp. 185-216.

Causer, T., and Terras, M. 2014. "Many Hands Make Light Work. Many Hands Together Make Merry Work: Transcribe Bentham and Crowdsourcing Manuscript Collections," in Crowdsourcing Our Cultural Heritage, M. Ridge (ed.). England: Ashgate Publishing limited, pp. 57-88.

Constantinidis, D. 2016. "Crowdsourcing Culture: Challenges to Change," in Cultural Heritage in a Changing World, K.J. Borowiecki, N. Forbes and A. Fresa (eds.). Switzerland: Springer Nature, pp. 215-234.

Corney, J., Lynn, A., Torres, C., Di Maio, P., Regli, W., Forbes, G., and Tobin, L. 2010. "Towards Crowdsourcing Translation Tasks in Library Cataloguing, a Pilot Study," Digital Ecosystems and Technologies (DEST), 2010 4th IEEE International Conference on, pp. 572-577.

Covarrubias, M. 2008. Island of Bali. Singapore: Periplus Editions (HK) Limited.

Davis, F. D. 1989. "Perceived Usefulness, Perceived Ease of Use, and User Acceptance of Information Technology," MIS quarterly (13:3), pp. 319-340.

Davis, F. D., Bagozzi, R. P., and Warshaw, P. R. 1989. "User Acceptance of Computer Technology: A Comparison of Two Theoretical Models," Management science (35:8), pp. 982-1003.

de Vreede, T., de Vreede, G.-J., and Reiter-Palmon, R. 2017. "Antecedents of Engagement in Community-Based Crowdsourcing," Proceedings of the 50th Hawaii International Conference on System Sciences, Hawaii, pp. 761-770.

Dixon, R. M. 1997. The Rise and Fall of Languages. Cambridge: Cambridge University Press.

Fishman, J. A. 2001. Can Threatened Languages Be Saved?: Reversing Language Shift, Revisited: A 21 st Century Perspective. Clevedon: Multilingual Matters.

Galla, C. K. 2016. "Indigenous Language Revitalization, Promotion, and Education: Function of Digital Technology," Computer Assisted Language Learning (29:7), pp. 1137-1151.

Genee, I., and Junker, M.-O. 2018. "The Blackfoot Language Resources and Digital Dictionary Project: Creating Integrated Web Resources for Language Documentation and Revitalization," Language Documentation \& Conservation (12:1), pp. $274-314$.

Hair, J. F., Anderson, R. E., Tatham, R. L., and Black, W. C. 1998. Multivariate Data Analysis, (5th ed.), New Jersey: Prentice-Hall International, INC.

Hasanah, R. L., Wati, F. F., and Riana, D. 2019. "Tam Analysis on the Factors Affecting Admission of Students for Ruangguru Application," Jurnal Sistem Informasi (Journal of Information System) (15:2), pp. 1-14.

Hermes, M., and King, K. A. 2013. "Ojibwe Language Revitalization, Multimedia Technology, and Family Language Learning," Language Learning \& Technology (17:1), pp. 125-144.

Kemdikbud. 2018. "Badan Bahasa Petakan 652 Bahasa Daerah Di Indonesia." July 24. (https://www.kemdikbud.go.id/main/blog/2018/07/badan-bahasa-petakan-652-bahasa-daerahdi-indonesia, accessed 01 November, 2019)

Leon, S. M. 2014. "Build, Analyse, and Generalise: Community Transcription of the Papers of the War Department and the Development of Scripto," in Crowdsourcing Our Cultural Heritage, M. Ridge (ed.). England: Ashgate Publishing limited, pp. 89-111.

Litman, L., Robinson, J., and Rosenzweig, C. 2015. "The Relationship between Motivation, Monetary Compensation, and Data Quality among Us-and India-Based Workers on Mechanical Turk," Behavior research methods (47:2), pp. 519-528. 
Mao, K., Capra, L., Harman, M., and Jia, Y. 2017. "A Survey of the Use of Crowdsourcing in Software Engineering," Journal of Systems and Software (126:1), pp. 57-84.

Nunnally, J. C., and Bernstein, I. H. 1994. Psychometric Theory, (3rd ed.). New York: McGraw-Hill.

Pramartha, C., and Davis, J. G. 2016. "Digital Preservation of Cultural Heritage: Balinese Kulkul Artefact and Practices," in Digital Heritage. Progress in Cultural Heritage: Documentation, Preservation, and Protection: 6th International Conference, Euromed 2016, Nicosia, Cyprus, October 31 - November 5, 2016, Proceedings, Part I, M. Ioannides, E. Fink, A. Moropoulou, M. Hagedorn-Saupe, A. Fresa, G. Liestøl, V. Rajcic and P. Grussenmeyer (eds.). Cham: Springer International Publishing, pp. 491-500.

Pramartha, C., Davis, J. G., and Kuan, K. K. Y. 2017. "Digital Preservation of Cultural Heritage: An Ontology-Based Approach," The 28th Australasian Conference on Information Systems, Hobart, Australia, pp. 1-12.

Pramartha, C., and Dwidasmara, I. B. G. 2014. "The Composition Approach Non-Qwerty Keyboard for Balinese Script," Humanitarian Technology Conference - (IHTC), 2014 IEEE Canada International, Montreal, Canada, pp. 1-4.

Suarta, I. M., and Suwintana, I. K. 2015. "The Influence of E-Learning Characteristics and Basic Ict Competencies to Actual Usage of E-Learning: A Path Diagram Model," Jurnal Sistem Informasi (Journal of Information System) (11:2), pp. 59 - 67.

Tabachnick, B. G., and Fidell, L. S. 2001. Using Multivariate Statistics, (4th ed.), Boston, MA: Allyn and Bacon.

Ullah, I. 2019. "Digital Dictionary Development for Torwali, a Less-Studied Language: Process and Challenges," Proceedings of the Workshop on Computational Methods for Endangered Languages, Honolulu, Hawai, USA, pp. 11-16.

\section{How to cite:}

Pramartha, C., Iswara, I. B. A. I., and Mogi, I. K. A. 2020. "Digital Humanities: Community Participation in the Balinese Language Digital Dictionary," Jurnal Sistem Informasi (Journal of Information System) (16:2), pp. 18-30. 